\title{
Caring for children with specialized health care needs in the community: the challenges for primary care
}

\author{
Susan Kirk \\ National Primary Care Research and Development Centre, The University of Manchester, Manchester, UK
}

\section{Correspondence}

Susan Kirk

National Primary Care Research

and Development Centre

$5^{\text {th }}$ floor, Williamson Building

The University of Manchester

Oxford Road

Manchester M13 9PL

UK

\begin{abstract}
People needing intensive and specialized health care are being cared for now in community settings; this has implications for both primary health care professionals and family carers. This paper draws on research investigating how services can be developed to support families caring for children with complex health care needs, to consider the challenges facing professionals working in the primary health care sector. Interviews conducted with parents, professionals and those who fund and commission specialized health services reveal particular problems in relation to the purchasing and provision of short-term care and specialist equipment/therapies in the community. These problems need to be addressed if people with specialized needs are to be cared for outside hospitals. The new Primary Care Groups (PCGs) will have the opportunity to enhance the provision of these services. Primary care professionals will also need to work in partnership with other sectors of the health service and with local authority services, at both strategic and operational levels, to develop integrated and coordinated services for this growing group of people.
\end{abstract}

Keywords: interagency collaboration, inter-professional collaboration, paediatric home care, primary health care, specialized health care

\section{Introduction}

An increasing policy emphasis has been placed during the 1990s on the community and primary health care sectors as the arena for long-term care; this has led to people with long-term needs being cared for in community rather than institutional settings. Intensive and specialized health care has started to move out of the hospital and into domiciliary settings; this is evident in the growth of hospital-at-home schemes, palliative care services and other domiciliary services for people needing high-technology care (Marks 1991, Steiner 1997). The increase in the level of care that is being provided outside the hospital has implications for both primary health care professionals and family carers (Kirk \& Glendinning 1998). This paper will draw on research that is investigating how services can be developed to support families caring for children with complex health care needs, in order to consider the challenges facing professionals working in the primary health care sector. In particular, what problems are faced in commissioning and providing health and other services for people with specialized health care needs living in the community? The implications for family carers, significant though they are, will not be the subject of this particular paper.

The research focuses on a group of children who need a variety of high-tech medical technologies, either on a continuous or intermittent basis, to survive; a group termed 'technology-dependent' in North America. They are a group of children who have recently emerged as a result of medical advances which have enabled pre-term infants, children with congenital malformations, and children with chronic illnesses and cancers both to survive and to survive for longer. In addition, over the last 40 years government policy has emphasized the need to care for sick children out of hospital wherever possible (Ministry of Health 1959, DHSS 1976, Department of Health 1991). In response to this policy aim, community childrens' 
nursing (CCN) teams have been developing, albeit slowly until the 1990s, when the pressures on hospitals to increase bed occupancy rates provided added impetus for their establishment. However, such teams have not been established in every area of the UK. It has been suggested that only $30 \%$ of children live in an area where there is a CCN service, with only $10 \%$ having access to a 24-hour service (Tatman \& Woodroffe 1993); and that only 50\% of health authorities purchase a CCN service (House of Commons Health Committee 1997). Other community-based nurses such as health visitors and district nurses, therefore continue to play a significant role in the care of sick and disabled children and their families. In some medical specialities, nurse specialist posts have been developed to provide expert nursing support for parents and children in both hospital and home settings and for professionals working in the secondary and primary care sectors.

As a result of these changes, complex nursing care and sometimes highly technical procedures are now being carried out in the home by parents (and in some cases by the children themselves). At present very little research has been conducted in the UK which has investigated the needs of such families and their perceptions of the services supporting them at home. Research conducted in North America highlights the social, emotional and financial impact on parents and the problems families may encounter in obtaining and maintaining appropriate services (Kirk 1998). There is also a lack of information on the size of the population in the UK with such needs (Glendinning et al. 1999).

It is likely that many of the issues presented in this paper will have a wider relevance for other groups of people with intensive and specialized needs, such as adults with head injuries or high-tech health care needs, as well as people being cared for by hospital-athome or rapid response schemes. The changing interface between the hospital and primary care sectors has implications for primary health care professionals not just as service providers. The PCGs established following the National Health Service (NHS) white paper (Department of Health 1997) will also have responsibility for purchasing and arranging specialist communitybased services in their areas. Therefore some of the challenges for health authorities highlighted in this paper will be ones which PCGs may need to address in the future.

\section{Methodology}

This study has taken a qualitative approach in order to obtain insights into the experiences of this group of families and the professionals supporting them in the community.

\section{Aims of the study}

1 To explore the experiences of families caring at home for a technology-dependent child,

2 to identify problems and good practice in the purchasing, delivery and coordination of services,

3 to assess the appropriateness and adequacy of support services, particularly the specialist expertise amongst generic community-based health professionals and the coordination of multipleservice inputs for families with very complex needs.

\section{Interviews with parents and children}

Qualitative interviews were conducted with the parents of 24 children who were dependent on technology and with four of the children themselves. These families were recruited via three specialist childrens' hospitals in the north of England, with the assistance of nurse specialists and hospital consultants. Families were purposively selected to include a range of technologies; variations in the lengths of time that their children had been cared for at home; and a variety of nursing support services in the home. These were the theoretical issues which an earlier research review and discussions with service providers had suggested could influence the experience of caring for a technologydependent child. During the course of the fieldwork it emerged that the distance the family lived from the specialist hospital could also influence parents' experiences and help-seeking behaviour, so this variable was incorporated into sampling of families.

The hospitals contacted each family with information about the research and obtained consent to pass on their details to the researcher. Families were then contacted by the researcher to discuss further their willingness to participate in the study, to answer any questions they might have and to arrange a convenient appointment. Written informed consent to participate in the research was obtained at the time of the interview. In seven families it appeared feasible to interview the child and with parental consent these children were contacted with an information sheet about the study. Four of these children subsequently agreed to be interviewed.

As Table 1 illustrates, the children in the sample were dependent on a variety of technologies, many of them on more than one. They ranged in age from 4 months to 17 years. The majority had been at home for between 1 and 3 years.

\section{Interviews with professionals}

Parents interviewed in the study provided the researcher with the names of all the professionals supporting 
Table 1 The technological dependencies of the children in the sample $(n=24)$

\begin{tabular}{lc}
\hline Technological dependence & Number \\
Tracheostomy & 10 \\
Oxygen therapy & 8 \\
Mechanical ventilation & 6 \\
Intravenous drugs & 4 \\
Parenteral nutrition & 2 \\
Peritoneal dialysis & 2 \\
Others (e.g. Gastrostomy) & 13 \\
\hline
\end{tabular}

Table 2 The sample of professionals $(n=44)$

\begin{tabular}{ll}
\hline Professional & Number \\
Clinical nurse specialists & 7 \\
Community childrens' nurses & 5 \\
Health visitors & 5 \\
District nurses & 4 \\
Home carers & 4 \\
General practitioners & 4 \\
Community-based social workers & 4 \\
Community paediatricians & 3 \\
Hospital social workers & 3 \\
School head teachers/teachers & 2 \\
Health authority purchasers & 3 \\
\hline
\end{tabular}

them in the home care of their child. From this sampling frame, 38 professionals involved in supporting the families at home were sampled and interviewed in depth about their experiences. Purposive sampling ensured that the sample included a range of different professional groups, technologies used by the children and geographical areas (both near to and far from specialist centres and areas with and without CCN teams). In addition, three health authority officers responsible for purchasing services for this group of children were interviewed, as were three nurses responsible for planning childrens' discharge from hospital (Table 2).

\section{Analysis}

All the interviews with parents, children and professionals (apart from three) were tape-recorded and fully transcribed. Where it was not possible through lack of consent to use a tape-recorder, notes were taken during the interview. The transcripts and interview notes were coded line-by-line to identify conceptual labels which in turn were grouped together to form categories. This process of analysis is termed open coding (Strauss \& Corbin 1990). A computer package (NUD*IST) was used as a tool to support the coding and exploration of the data generated.

\section{Findings: the challenges for primary health care professionals}

The analysis of the data revealed a number of important issues and challenges for primary health care professionals; both as purchasers and as the providers of services. The particular primary health care professionals who are the subject of this paper are health visitors, district nurses and general practitioners (GPs).

\section{The commissioning of appropriate short-term care and home-support services}

The nature of the care that parents were providing for the children in this study was complex and included procedures that would until recent years have been considered the domain of professional health care workers. Many of the children in the study had intensive needs; some required 24-hour care and supervision, which placed considerable pressure on parents. Often family and friends could not assist in caring for the child unless they had also undergone training, so parents were reliant on formal services to obtain a break from caring. However, the majority of professionals felt that local short-term care services were usually inappropriate because of the nature of the nursing care this group of children required. Night-sitting services were reported to be either non-existent or provided only for adults or for people with cancer. Family based short-term care (where a child goes to stay with another, specially recruited family) had been used by only one family. Thus in the majority of cases, home carers had been recruited and trained specially to support families in the home (and in some cases the children in school), by providing a regular break in caring for the child either during the day or overnight. Where children had particularly intensive needs (for example, needing continual ventilatory support), home carers assisted parents in caring for their child at home on a daily basis. Professionals noted that both appropriate individualized and specialized short-term care and home-support services need to be planned in advance, not on a crisis basis, because of the lengthy process involved in recruiting and training carers.

Obtaining such services was, however, not straight forward for families. Both parents and professionals reported that they had been aware of lengthy disputes between health authorities and local authority social service departments over who was responsible for funding short-term care and home-support workers. These funding disputes often led parents to feel that they had had to fight for short-term care at a time when they were already under considerable stress. It appeared in most localities to be unclear where 
funding responsibilities for short-term care lay and therefore open to local interpretation; this resulted in differences in the services available in different areas. In some areas, health authorities and local authorities each funded separate services for the same families, whilst in others it appeared that the health authority was the sole purchaser. One hospital unit used charitable funding to enable nurses from a hospital ward to provide short-term care for families at home. In two areas, the health authority and local authority funded integrated home care packages jointly (and equally). This had resolved to a great extent any disputes over the funding of short-term care and home carers.

Not only did the funding arrangements differ, but families also received a diverse range of home-support services, from a few hours once a week to 24-hour 365 days a year and variously provided by professional nurses or trained lay support workers. The level of support received did not always appear to relate to the families' level of need; families with similar needs but living in different areas could differ in the level and type of support they were receiving. Most families had individuals or teams of carers employed and trained specifically to care for their child, but some were utilizing nursing auxiliaries from the district nursing team, night-time carers from a specialist cancer service, volunteers recruited by local carer support organizations, agency nurses, foster carers and family aides. A number of problems were reported in relation to such workers - including their recruitment, retention, training, supervision and relationships with the families - which are beyond the scope of this paper.

Although home based support and respite care could result in a lack of privacy for families, the families themselves viewed it as being overwhelmingly preferable to institutionally based short-term care, such as childrens' hospices or short-term care wards in hospital. The reasons given by parents for this were that home based services were more flexible; the child remained in his/her own familiar environment; large amounts of equipment did not have to be transported; the risk of cross-infection was reduced; and homebased, short-term care was provided by one carer or a team of carers whom the child and parents trusted and who had an in-depth knowledge of the individual child's care needs. The use of non-professional staff was seen by parents to be acceptable.

\section{The purchasing and provision of specialist equipment in the home}

This group of children by definition have substantial needs for a variety of specialized equipment and drug products. These vary from pieces of equipment such as ventilators, suction machines and infusion pumps, to consumables such as gastrostomy tubes, syringes, suction catheters and drug products (for example, antibiotics, oxygen and nutrient solutions). The research revealed, however, that the purchasing and provision of equipment could be problematic for both parents and professionals.

\section{Funding disputes}

Parents and health professionals reported disputes arising between hospitals, community health services and GPs over who was responsible for funding the equipment and medications that the children required at home. Professionals and parents had both experienced situations where GPs had been unwilling to prescribe some or all of the consumables that were needed, because of the impact on their prescribing budgets. Disputes could occur within hospital and community health service trusts themselves, over which directorate's budget should fund equipment. Community trusts and health authorities could also have different opinions over whether or not the equipment needed by this group of children formed part of an existing service agreement between the two organizations. Some health authorities used their extracontractual referrals (ECR) budget to purchase equipment (and home care support), as this was the only source of revenue available for them to use for such unpredictable demands. Some families felt that they had had to fight to get appropriate equipment and were aware through informal networks that local services could differ in their willingness to fund certain pieces of equipment.

This lack of clarity over funding responsibilities could lead to considerable time and effort being spent by health professionals, such as district nurses and health visitors, in obtaining agreements on how specific pieces of equipment and the ongoing supply of consumables were to be funded and supplied to families. Responsibilities and mechanisms for funding and providing equipment and consumables for children dependent on those therapies detailed in policy guidance EL(95)5 (National Health Service Executive 1995) (peritoneal dialysis, some intravenous drugs and parenteral nutrition) appeared to be far clearer than for those children in the sample who were dependent on therapies not covered by this guidance (mechanical ventilation, tracheostomy, oxygen therapy and enteral feeding).

Some community health professionals noted that there were no additional funds to allow community trusts and GPs to meet the increasing numbers of technology-dependent children in the community, as 
resources had not 'followed the child' out of hospital. Whilst the health authority purchasers were also aware of this, they were also aware that disinvestment in the hospital sector was unpopular with both the public and hospital professionals, attracting negative media coverage and local campaigns. They were therefore reluctant to move resources from hospitals and appeared to see the solution more in terms of aligning the funding and clinical responsibilities within trusts, with the costs of home care clearly forming part of the service agreement between the health authority and the trust.

\section{Provision of equipment and drug products}

A diversity of arrangements were found in the actual provision of consumables to families with technologydependent children. General practitioners, local pharmacists, hospital pharmacists, clinical nurse specialists, community childrens' nurses, district nurses, health visitors and commercial companies - all played a role in supplying this group of families with the equipment and drug products their children required. For many families, consumables could be supplied by two or more different providers.

A number of families criticized GPs, district nurses and health visitors for their unreliability in organizing and supplying equipment. The ordering and delivery of equipment could be forgotten, the wrong equipment ordered or the prescription completed incorrectly. Parents who received supplies via primary health care professionals therefore often relied on the specialist hospital to provide supplies in an emergency, which was problematic for those families living at a distance from the hospital. A number of parents collected large quantities of sometimes heavy supplies on a regular basis from local pharmacists and health centres. For some families, problems in obtaining adequate supplies were a source of considerable stress and ensuring that they had sufficient supplies to care for their child was an essential part of their daily routine. Some parents had had disputes with primary health care professionals over the quantities of consumables needed to care for their child. Parents reported that they had been made to feel, particularly in the early days following discharge, that they were using too much equipment. District nurses and health visitors, parents felt, did not always understand that parents could not predict the length of time that their child would need the equipment or the amount of supplies which would be required on a weekly basis, because of the unpredictable nature of the child's care needs. The supply of equipment appeared to be particularly problematic for those children with tracheostomies.
In a small number of cases, children had been discharged home only for parents to find different types of equipment were supplied from those they had been taught to use in hospital. Some parents also reported that equipment servicing and repair contracts and clinical waste collection services had not been arranged before the child's discharge and two parents had been unable to obtain the latter altogether.

In contrast, some families received some or all of their equipment directly from commercial companies. In these instances, families were highly satisfied with the provision of equipment, which was reported to be everything that supplies provided by primary health care professionals were not - reliable, efficient, responsive, integrated and delivered straight to the families' homes. The families in receipt of such services were largely those whose children needed peritoneal dialysis and intravenous drugs, although some families with children needing enteral feeding or oxygen therapy also received some equipment via commercial home care companies.

The provision of equipment was not just problematic for parents; community nurses also frequently described it as a 'nightmare' because of funding disputes and the often considerable amount of time they could spend sorting out equipment problems. The specialized equipment which the children needed usually did not form part of existing community stocks and therefore had to be ordered specially for each individual child. Community trusts could also be unfamiliar with equipment for sick children (especially if they did not employ a CCN team). They could experience difficulties managing the ordering and supply of sometimes very specialized equipment for children whose needs not only changed as they grew, but whose medical condition was also unpredictable. In addition, community health professionals were frustrated that hospitals did not always give them sufficient time to order the equipment needed and were not aware of what was readily available in the community. Thus on discharge, children could be prescribed specialized medications or other products by the hospital, which GPs were either unable to prescribe or which local pharmacists did not routinely stock.

\section{Working in partnership with other professionals and organizations}

Although the families continued to receive support from a specialist hospital, particularly from the clinical nurse specialists based there, it was clear from the interviews that some primary health care professionals were also playing a role beyond the provision of equipment, in supporting the families and helping 
them obtain local services. This was particularly the case where there was no local CCN service or where families lived some distance from the specialist centre. However, a number of families were dissatisfied with the level of support they had received from primary health care professionals. They felt that primary health care professionals had avoided them through fear of the type of care their child needed. Parents were, however, aware that GPs, health visitors and district nurses lacked specialist knowledge and consequently they had few expectations of them being able to provide specialist medical or nursing advice.

A number of different organizations and professionals were often involved with families, yet services rarely appeared to be coordinated at an operational level. Few families had designated key workers or care managers, although this was seen as being very important by both professionals and parents. For parents, this had often drawn them into coordinating the various services and equipment themselves, which created additional pressures over and above those of caring for their child.

Post-discharge multi-disciplinary meetings to plan care jointly and anticipate future service needs were reported to be rarely held unless there was a crisis or a statutory requirement (for example, a child protection issue or an educational review). Some community nurses were dissatisfied with discharge planning, reporting that they were not always adequately involved or were given insufficient time by the hospital to arrange services or equipment locally. GPs were criticized for not attending discharge planning and other multidisciplinary meetings. The absence of coordinated service planning could lead to parents feeling overloaded with visits from professionals, with little time to establish a 'normal' family life; and to being confused over the respective roles and responsibilities of different professionals.

Communications across the community and hospital interface were reported to be poor by some parents and professionals and there was evidence to suggest that both hospital and community personnel had insufficient understanding of the contexts within which each other worked. Communication between the different professionals supporting families was often reactive and based on an assumption that communication was only needed if problems arose. Consequently, parents felt that they were sometimes over-relied upon to pass information between professionals.

The majority of professionals described the existence of good inter-professional relationships, although some nurse specialists and CCNs felt that GPs could be more receptive to their roles. However, the GPs interviewed appeared to have a very high regard for nurse specialists, in particular. There was evidence of the sharing of skills between nurses; clinical nurse specialists and CCNs shared their clinical expertise with community nurses, whilst community nurses shared their knowledge of local services with clinical nurse specialists and CCNs. There were also occasions when they worked closely together, jointly visiting families and schools. In some cases, district nursing services supported CCN services in the provision of out-ofhours care. However, there was the potential for much overlapping of roles and duplication of effort.

\section{Discussion}

This research revealed that moving the location of care for people with specialized health care needs from the hospital to the community presents a number of challenges for the primary care sector of the health service. In particular, there appeared to be considerable variation in the sources and levels of short-term care and home care services received by families, and in the division of responsibilities between health and social services for funding these particular services. Additionally, major problems were apparent in supplying specialized equipment, drugs and other consumable supplies to families and in ensuring that they received adequate amounts of these items to cover the unpredictable and fluctuating health needs of some children. Finally, there was evidence of some shortcomings in communication and coordination of services between hospital and community-based professionals and between community-based professionals themselves; these latter problems could lead to parents themselves adopting a major role in coordinating services and facilitating inter-professional communication.

\section{The challenges for primary care in commissioning services}

In developing their new responsibilities for commissioning services, primary health care professionals will need to work in collaboration with other organizations such as local authorities (Department of Health 1997). This will involve the new PCGs in commissioning individualized and integrated service 'packages' for people with specialized health care needs. This study found that disputes over the funding of shortterm care and home carers had been resolved to a great extent in those areas where care packages were jointly (and equally) funded by the health authority and local authority. A recent discussion document issued by the Department of Health suggests that such arrangements will be facilitated further by the introduction of legislation to enable the pooling of budgets 
(Department of Health 1998a). Although this will not resolve all joint working problems, it may remove the time delays and uncertainties that parents and other carers experience in obtaining such services. Shortterm care arrangements in general also suffer from a lack of strategic planning and the development of these services needs to be included in planning mechanisms such as local authority Childrens' Services Plans, continuing care agreements and Joint Investment Plans, when these are extended to children.

Primary care organizations are also likely to play an enhanced role in commissioning specialist hospital services (which may include clinical nurse specialist posts). In the past, GP fundholders and total purchasers (TPPs) have not purchased these services, because of the associated financial risk and the need for specialist skills and knowledge for effective commissioning. Instead, the purchasing of specialist hospital services has been the responsibility of health authorities, which in many areas have joined together and commissioned these services through consortium arrangements, where groups of health authorities within a region commission specialist services together with one health authority acting as a lead commissioner (Audit Commission 1997). New arrangements for commissioning these services from April 1999 will also include specialized regional commissioning groups. (This excludes services that are centrally commissioned through the National Specialist Commissioning Advisory Group) (National Health Service Executive 1998a, 1998b). However, it is anticipated that such groups will involve PCGs in discussion and decision making in relation to the commissioning of specialized services. Moreover, in future, it is likely that the commissioning of some specialized services will be devolved gradually down to the PCG level. Primary care organizations will then need to consider the most effective way of organizing this type of commissioning, for example through the establishment of PCG consortia. From 1999, PCGs will also be able to influence the further development of $\mathrm{CCN}$ and other specialist nursing teams through their commissioning roles.

In relation to specialist equipment and drug products, the study identified a lack of clarity over funding responsibilities and fragmentation of provision which urgently need addressing. NHS guidance EL(95)5 clarified responsibilities for funding certain technologies, and the associated use of commercial companies to provide an integrated service directly to parents' homes appears to have been of benefit to families; the provision of specialist equipment and drug products via commercial companies was highly valued by parents because of its reliability, efficiency, responsiveness and integration. However, such arrangements may often be a more expensive option for purchasers than the use of community trust staff to deliver equipment and supplies. The extension of EL(95)5 to other technologies and therapies and the use of commercial companies warrants evaluation by commissioners in health authorities and PCGs. Proposals to incorporate funding for unanticipated equipment and services within the service agreements negotiated between PCGs, health authorities and NHS trusts (National Health Service Executive 1998c) may clarify funding responsibilities between provider organizations and commissioners. However, the potential for disputes between hospital and community trusts and between NHS trusts and GPs remains, unless funding responsibilities are clearly identified in service agreements. Disputes between GPs and NHS Trusts could be resolved by removing the funding of specialized equipment and drug products from GP prescribing budgets (as in EL95(5)), with PCGs then contracting directly with either commercial companies or with specialist hospitals. The latter could then in turn choose to subcontract this service to private companies or to provide it themselves. The use of a lead commissioner acting on behalf of a number of PCGs, as advocated by Pilling \& Walley (1995), would be one method for PCGs to organize the purchasing of specialized equipment and drug products.

\section{The challenges for primary health care professionals as practitioners}

As a number of reports have advocated, all families with a sick or disabled child should have access to a local CCN service, but at present this is not the case (DHSS 1976, Audit Commission 1993, House of Commons Health Committee 1997). When a CCN service is not provided locally, primary health care professionals will need to assess how they can fill this gap in service provision, in collaboration with other professionals and in consultation with the families themselves.

Primary health care professionals have a role to play with people with specialized health care needs and their families in providing family support, giving information, facilitating access to local services and coordinating services. This role also needs to recognize and acknowledge parents' and carers' expertise and active participation in their children's care, whilst responding sensitively to their individual needs for support. This study showed that primary health care professionals cannot work in isolation with people who have specialized health care needs. Their needs are complex, requiring the intervention of a range of professionals and workers from a variety of organizations. Consequently it is important for professionals to 
work in collaboration to deliver coordinated and integrated services. Possible mechanisms for this include the creation of multi-disciplinary teams, the use of key workers/care managers, and the utilization of integrated care pathways/programmes.

The need for good inter-professional and interagency working specifically in relation to childrens' services has been advocated in many reports and policy documents over the last 20 years (DHSS 1976, The Children Act 1989, The Education Act 1993, Thornes 1993, Audit Commission 1994, Department of Health 1996, 1998b,c, Hogg 1996, House of Commons Health Committee 1997). However, it is apparent from this study that there remain inter-agency disputes over funding responsibilities and that the goal of delivering coordinated and seamless services which transcend organizational and professional boundaries has yet to be attained. There remains a significant role for primary care in developing and delivering coherent and coordinated services for people with specialized health care needs.

\section{Acknowledgements}

The research reported in this paper has been funded by the Department of Health's 'Supporting Parents' initiative. The views expressed in this paper are those of the author and not those of the Department of Health.

\section{References}

Audit Commission (1993) Children First: A Study of Hospital Services. HMSO, London.

Audit Commission (1994) Seen But Not Heard: Coordinating Community Child Health and Social Services For Children. HMSO, London.

Audit Commission (1997) Higher Purchase: Commissioning Specialised Services in the NHS. Audit Commission, London.

Department of Health (1991) Welfare of Children and Young People in Hospital. HMSO, London.

Department of Health (1996) Child Health in the Community: a Guide to Good Practice. HMSO, London.

Department of Health (1997) The New NHS: Modern, Dependable. HMSO, London.

Department of Health (1998a) Partnership in Action: New Opportunities for Joint Working Between Health and Social Services. HMSO, London.

Department of Health (1998b) Evaluation of the Pilot Project
Programme for Children With Life-Threatening Illnesses. HMSO, London.

Department of Health (1998c) Disabled Children: Directions for Their Future Care. HMSO, London.

Department of Health and Social Security (1976) Fit for the Future the Report of the Committee on Child Health Service (Court Report). Cmnd 6684.

Glendinning C., Kirk S., Guiffrida A. \& Lawton D. (1999) The Community-Based Care of Technology Dependent Children in the UK: Definitions, Numbers and Costs. National Primary Care Research and Development Centre, Manchester.

Hogg C. (1996) Health Services For Children and Young People: a Guide For Commissioners and Providers. Action for Sick Children, London.

House of Commons Health Committee (1997) Health Services for Children and Young People in the Community: Home and School. The Stationary Office, London.

Kirk S. (1998) Families experiences of caring at home for a technology-dependent child: a review of the literature. Child: Care, Health and Development 24 (2), 101-114.

Kirk S. \& Glendinning C. (1998) Trends in community care and patient participation: implications for the roles of informal carers and community nurses in the United Kingdom. Journal of Advanced Nursing 28 (2), 370-381.

Marks L. (1991) Home and Hospital Care: Redrawing the Boundaries (Research Report 9). Kings Fund, London.

Ministry of Health (1959) The Welfare of Children in Hospital: Report of The Committee (The Platt Report). HMSO, London.

National Health Service Executive (1995) Purchasing HighTech Health Care for Patients at Home. EL(95)5. NHSE, Leeds.

National Health Service Executive (1998a) The New NHS: Commissioning Specialist Services (Consultation Document). NHSE, Leeds.

National Health Service Executive (1998b) Commissioning in the New NHS. HSC 1998/198. NHSE, Leeds.

National Health Service Executive (1998c) The New NHS: Guidance on Out of Area Treatment (Consultation Document). NHSE, Leeds.

Pilling M. \& Walley T. (1995) Purchasing High-Tech Healthcare for Patients at Home. Department of Pharmacology and Therapeutics, University of Liverpool.

Steiner A. (1997) Intermediate Care: a Conceptual Framework and Review of the Literature. Kings Fund, London.

Strauss A. \& Corbin J. (1990) Basics of Qualitative Research: Grounded Theory Procedures and Techniques. Sage, Newbury Park, California.

Tatman M. \& Woodroffe C. (1993) Paediatric home care in the UK. Archives of Disease in Childhood 69, 677-680.

The Children Act (1989) HMSO, London.

The Education Act (1993) HMSO, London.

Thornes R. (1993) Bridging The Gaps: An Exploratory Study of The Interfaces Between Primary and Specialist Care for Children Within The Health Service. Action for Sick Children, London. 